\title{
Cultural differences in clinical leadership: a qualitative study comparing the attitudes of general dental practitioners from Greater Manchester and Tokyo
}

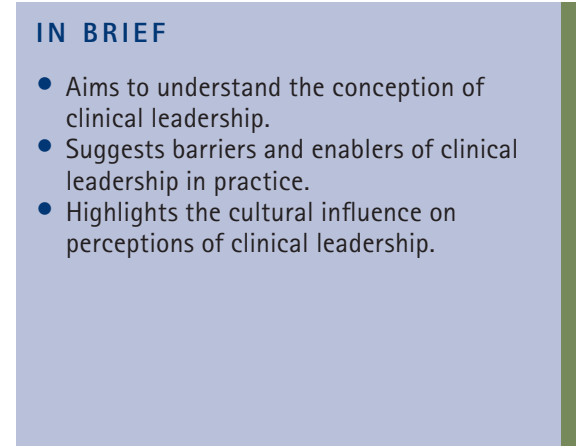

\author{
P. Brocklehurst, ${ }^{* 1}$ M. Nomura, ${ }^{2}$ T. Ozaki, ${ }_{1}^{3}$ J. Ferguson ${ }^{4}$ and R. Matsuda ${ }^{5}$
}

Background and aims Leadership has been argued to be a key component in the transformation of services in the United Kingdom and in Japan. In the UK, local professional networks have developed to provide clinician led care in dentistry; working to develop local plans to deliver improvements in the quality of care for patients. In Japan, the remuneration model for dental care has been revised with the aim to improve the service and tackle the current challenges of population health there. The aim of this study was to use semi-structured interviews and thematic analysis to explore general dental practitioners' (GDPs) understanding of the term 'leadership' and determine whether its meaning is culturally bound. Methods Twelve participants were sampled purposively by the research team; identifying GDPs involved in leadership roles from across Greater Manchester and Tokyo. A set of open-ended questions was developed for semi-structured interviews a priori and the interviews continued until saturation. Interviews were recorded, transcribed verbatim and codes were developed into a coding frame for thematic analysis. Representative quotations are provided in the results. Results Fourteen codes were identified according to the aims of the study and organised into five overarching themes. 'Leadership as the relationship' was more pronounced among Japanese GDPs, while 'leadership as the individual' was common in GDPs from Greater Manchester. Differences were also found in respect of education and training in leadership. Training was also considered to be important by the GDPs from Japan, while UK GDPs felt leaders were more likely to be influenced by innate qualities. The interdependence of leadership and entrepreneurship was raised by both sets of GDPs. Conclusion The concept of leadership was considered to be important by GDPs from both Greater Manchester and Tokyo; leadership was seen as providing strategy and direction for a clinical team. However, cultural influences were evident in how this was conceptualised.

\section{INTRODUCTION}

In 2011 in the United Kingdom, the King's Fund published a report on leadership in the National Health Service (NHS), which argued for an approach that involved the whole clinical and management team. ${ }^{1}$ This was followed in 2012 by Leadership and engagement for improvement in the

\footnotetext{
Senior Clinical Lecturer and Honorary Consultant in Dental Public Health, Department of Dental Public Health, University of Manchester, Manchester, UK: ${ }^{2}$ Representative Director, Healthcare Research Inc. Japan; ${ }^{3}$ Professor in Community Dentistry, Nihon University Dental School, Japan; ${ }^{4}$ Department of Dental Public Health, University of Manchester, Manchester, UK; ${ }^{5}$ Professor in Community Health and Health Policy and Director of the Institute of Human Sciences, College of Social Sciences, Ritsumeikan University, Japan. *Correspondence to: Dr Paul Brocklehurst Email: paul.brocklehurst@manchester.ac.uk
}

\section{Online article number E19}

Refereed Paper - accepted 30 July 2013

DOI: 10.1038/sj.bdj.2013.1096

British Dental Journal 2013; 215: E19
NHS, which extolled the importance of leaders in improving population health and patient care. ${ }^{2}$ In primary care, these calls are concomitant with the move towards clinically led commissioning, with effective leadership being increasingly articulated as critical to the greater integration of services around the needs of patients and populations..$^{2-4}$

For some general dental practitioners (GDPs), leadership within the NHS would appear to be rather removed from the dayto-day experience of practice life, where the size of the team is relatively small and where care is limited to a familiar patient base rather than a local population. However, the Government's Health and Social Care Act has culminated in the concept of local professional networks for dentistry (LPNs). ${ }^{4}$ The LPNs in dentistry are part of the substantive reform in the NHS in England and are analogous to the clinical commissioning groups in medicine. They are designed to provide clinician led care in dentistry; working to deliver local plans to deliver improvements in the quality of care for patients. ${ }^{5}$

Similar changes are occurring in Japan, where the remuneration model for medical, dental and long-term care has been revised with the aim to improve the service and tackle the current challenges of population health in the country. With the ageing population, GDPs in Japan are increasingly being required to work with other healthcare professionals to improve the oral health of the elderly and patients with chronic conditions. They are also expected to provide continuous care for patients moving between the community and hospitals. This is highlighted in the recent Annual health, labour and welfare 
report 2011-2012, which seeks to address the future demographic challenges in the Definite plan for the comprehensive reform of social security and tax. ${ }^{6}$ Again, clinical leadership has been argued to be a key component of this transformation.

The aim of this study was to use thematic analysis to explore GDPs' understanding of the term clinical leadership and determine whether its meaning is culturally bound. Qualitative methods have been increasingly used in healthcare research and elicit the unique meaning that people attach to their experiences. ${ }^{7}$ As such, it is particularly useful where the literature is sparse, for an understanding of the importance of clinical leadership in a primary dental care environment.

\section{METHODOLOGY}

\section{Participants}

Ethical approval was provided by the University of Manchester Ethics Committee (12057) and was considered to be low risk by the Nihon University School of Dentistry in Japan. Participants were sampled purposively by the research team; GDPs involved in leadership roles within the shadow LPN in Greater Manchester and in the Metropolitan Tokyo and Kanagawa prefectures. Three owner-principle and three salaried dentists were invited from members of the Japanese Society of Dental Practice Administration. The salaried dentists worked mainly in hospital, but in the Japanese system they also work occasionally in private dental offices. Participants were contacted initially by e-mail and then followed up to arrange an interview at their convenience. The study was funded by the Great Britain Sasakawa Foundation $(£ 2,000)$ to promote research between the UK and Japan.

\section{Procedure}

A set of opening questions was developed for the semi-structured interviews from existing research on leadership in non-dental clinical settings and crosscultural studies. In accordance with Carter and Henderson, these were open-ended questions and investigated the following areas: attributes and characteristics of clinical leadership; differences between clinical leadership and leadership in a non-clinical setting; management and entrepreneurship; barriers to effective leadership; and the importance of training. ${ }^{8}$

The number of interviews undertaken was in accordance with the qualitative paradigm and so continued until saturation. ${ }^{7}$ The interviews were recorded on a Sony Digital Recorder, ICD-P110 and the audio-files transcribed into MS Word documents and line numbered for thematic analysis to develop a coding frame.'

The audio-files in Japan were translated by consensus, given the difficulties of expressing some of the complex cultural meanings (PRB, RM, MN). Two of the authors (PRB and MN) had been present at all the interviews in Japan to ensure validity. Overarching themes were developed from the coded transcripts by organising them into clusters based on the similarity of their meaning (PRB, RM, MN). ${ }^{7}$ These were then checked against the coded extracts and the raw data to ensure that they formed a coherent pattern and were representative of what the participants were trying to convey. Specific examples were selected to create clear definitions for the coding frame and representative quotes of each theme are given in the results; 'Tk' denoting quotes from Tokyo GDPs and 'GM' denoting quotes from Greater Manchester GDPs. A statement of reflexivity is provided to ensure transparency. ${ }^{9}$

\section{Reflexivity}

Dr Paul Brocklehurst is a NIHR Clinician Scientist and a consultant in dental public health. Having spent 15 years in practice, he was aware of the importance of leadership at a local practice level. Although Dr Nomura and Professor Matsuda were experienced health service researchers in medicine, they did not have any preconceptions on the role of leadership in dentistry.

\section{RESULTS}

\section{Demographics}

Five of the six participants in the Japanese study were members of the Japanese Society of Dental Practice Administration. All of the participants from Greater Manchester had experience in the shadow LPN for dentistry in Greater Manchester; two were also Local Dental Committee area representatives. The mean age of the participants was 47 years (range 30-75;
$\mathrm{SD}=13.1)$ and eight were men (66.7\%). With regard to professional experience, the mean number of years in dentistry was 23 years (range 8-46; $\mathrm{SD}=11.8$ ).

\section{Thematic analysis}

The thematic analysis produced a coding frame with 14 codes organised into five overarching themes (Table 1).

\section{Theme 1: characteristics of leadership}

\section{Code 1.1: What is leadership?}

All of the participants across both cultural groups were able to express what they thought leadership was and used terms that denoted the provision of strategy and direction:

Tk.4.8 'the leader is important for vision, strategy, policy and direction...'

Tk.3.8. 'it is the front-runner for change... introducing innovation and development.'

GM.2.342 'I mean leadership for me is to be able to take your team or take whoever is with you.... and have ideas on how to progress the vision, the thinking, the ethos.'

GM.5.235 'It's someone you prepared to follow...'

GM.6.219 'It's looking at the big picture...'

\section{Code 1.2: Attributes and behaviours}

Leaders were described as having a wide range of attributes and behaviours:

Tk.5.15 '...tolerance, acceptance, trust and reliability. The ability to make a decision. Determination...'

Tk.3.39 'Fairness is important, integrity and seriousness. Motivation and a spirit of commitment. Forward looking...'

Tk.6.70 'It is a mix of being supportive of your team and leading from the front...'

GM.2.402 'They have to be forward thinking, they have to have an open and flexible personality.'

GM.3.343 'I think you've got to be open minded, a good communicator, have enthusiasm... be able to spot good ideas and nurture other people...'

GM.4.251 'Being able to see the bigger picture, being able to motivate... being positive in your approach; being available.'

GM.5.327 'It's knowing the limitations of the team you're leading and encouraging them to exceed what they think are their own limitations... 


\section{Code 1.3: Influence of personality}

Another issue raised by all the GDPs was an awareness of their individual styles of leadership and how this was affected by their personality:

Tk.3.83 'My personality is an obstacle to good leadership. I want to do everything very quickly and I get impatient for change...'

Tk.4.73 'I think my weakness is to manage and go into too much detail, this can prevent my staff from reaching their potential...'

GM.1.448 'Leadership probably has got something to do with personality and I think my personality generally is fairly laid back...'

GM.2.452 'I have one or two issues with my own leadership... it's about delegating responsibility and trusting people...'

GM.5.382 'I'm very relaxed. I don't get stressed about anything that I can't do anything about.... so that can be a help or a hindrance...'

\section{Theme 2: role of leadership}

\section{Code 2.1: Clinical versus} non-clinical leadership

GDPs were asked whether there was any difference between clinical and non-clinical leadership. Some saw a difference:

Tk.5.38 'Clinical leaders should display good examples and models of clinical practice. I think this is different from general leadership...'

GM.3.308 'I find in a practice that I want to show all the staff that I actually really do care about the patients and to lead by example... leadership is leadership, but clinical, obviously you've got different aspects of patient care...'

Others saw no difference:

Tk.4.31 'I think it is similar. I need to involve many staff/stakeholders. In that sense it is similar...'

GM.2.378 'They are very similar, because at the end of the day you're motivating people....you're trying to get them to deliver tasks...'

GM.6.271 'No matter what you're doing the actual basic principles are not particularly specific to the role...'

\section{Code 2.2: Difference to management}

All of the clinicians understood and expressed a difference between leadership and management:

Tk.3.13 'Management is based on the existing situation and making progress step-by-step. Leadership is concerned more with the future...'

Tk.4.15 'Leadership is about setting a direction. Managers follow and support the leader...'

Tk.5.20 'Leadership is something that is inside of myself, management is something that is objectively observable...'

GM.5.252 'Management is just processes; anybody could follow if you set it out for them. You can manage a team of people, not necessarily be a leader of them.'

GM.6.237 'I'd have thought that most leaders are able to manage but not all managers would be able to lead.'

\section{Code 2.3: Entrepreneurship}

The impact of GDPs running their practices as a small business was articulated by both groups of clinicians:

Tk.2.27 'In Japan, dentists behave as both entrepreneurs and clinical leaders. I think dentists working in smaller clinics behave as clinical leaders more and more. Clinics are getting larger and are more based on entrepreneurship...'

Tk.3.21 'There is always conflict between clinical leadership and entrepreneurship. Economic issues are important. I like to treat my staff in a good way.... but as a business that may bring conflict...'

Tk.4.22 'I always feel there is a conflict between myself as a dentist and myself as an entrepreneur...'

GM.4.180 'If you go into many practices each dentist thinks they're their own leader.... each individual dentist is an associate, is a self-employed person in their own right...'

\section{Theme 3: Influence of culture}

\section{Code 3.1: Seniority, respect} and 'Senpai'

For all the Japanese participants, the concept of seniority, respect and 'Senpai' was expressed as an important component of leadership. The latter term relates to the importance of following your designated mentor and as a mentor, acting in a manner such that others will follow:

Tk.4.164 'A characteristic of the Japanese society is one of a closely connected community and this is reflected in how leaders behave.... I look at my Senpai...'

Tk.1.109 'In Japan, the people at the top have serious power, experienced senior people lead everything...'

Tk.2.210 'People do follow their leaders, this is a natural thing in our culture...'

Tk.6.51 'I follow the leader's back and by doing what I'm expected to do in my role, leadership follows...'

However, this idea of 'Senpai' can create problems in Japan:

Tk.2.164 'It is difficult for the junior staff to become leaders. For example, if you have a senior nurse and a junior doctor, the nurse will be the silent leader because of her seniority...'

Tk.3.155 'After the second world war, the egalitarianism principle has become a dominant social principle in Japan. So how to balance between egalitarianism principle and leadership is a difficulty...'

These concepts were not expressed by any of the dentists from Greater Manchester.

\section{Code 3.2: Relationships}

The importance of the relationship in leadership was also articulated among Japanese GDPs:

Tk.4.100 'I think leadership is relationship. Leadership doesn't exist otherwise...'

Tk.6.108 'Leadership is something that arises within a relationship...'

Tk.1.82 '...the relationship changes leadership...'

Tk.2.113 'Leadership can only be learnt through experiences in a relationship...'

This contrasted with the views of the dentists from Greater Manchester:

GM.3.294 'It's just one person, generally, and what you say goes. If you're the front order, you're the provider. You can discuss things with people, but actually you're at the top of the pyramid...'

GM.4.180 'If you go into many practices each dentist thinks they're their own leader... the leader maybe should be working more with a team approach but there hasn't necessarily been a team approach in dentistry...'

\section{Theme 4: How do you become a good leader?}

\section{Code 4.1: Role model}

Allied to the idea of 'Senpai' is the 


\begin{tabular}{|c|c|c|}
\hline Theme & Code & Description of the codes \\
\hline \multirow{3}{*}{$\begin{array}{l}\text { 1. Characteristics } \\
\text { of leadership }\end{array}$} & 1.1 What is leadership? & $\begin{array}{l}\text { Comments on the participants' understanding of leadership. For example 'The leader is important for vision, strategy, } \\
\text { policy and direction.' }\end{array}$ \\
\hline & $\begin{array}{l}1.2 \text { Attributes and } \\
\text { behaviours }\end{array}$ & $\begin{array}{l}\text { Comments on the attributes and behaviours that depict leadership. For example 'I think you've got to be open minded, } \\
\text { a good communicator, have enthusiasm. Be able to spot good ideas and nurture other people.' }\end{array}$ \\
\hline & $\begin{array}{l}1.3 \text { Influence of } \\
\text { personality }\end{array}$ & $\begin{array}{l}\text { Comments on the role of the participant's personality on leadership. For example 'My personality is an obstacle to } \\
\text { good leadership. I want to do everything very quickly and I get inpatient for change.' }\end{array}$ \\
\hline \multirow{3}{*}{$\begin{array}{l}\text { 2. Role of } \\
\text { leadership }\end{array}$} & $\begin{array}{l}2.1 \text { Clinical versus } \\
\text { non-clinical leadership }\end{array}$ & $\begin{array}{l}\text { Comments on the difference between leadership in a clinical and non-clinical environment. For example 'I find in a } \\
\text { practice that I want to show all the staff that I actually really do care about the patients and to lead by example' }\end{array}$ \\
\hline & $\begin{array}{l}2.2 \text { Difference to } \\
\text { management }\end{array}$ & $\begin{array}{l}\text { Comments on the difference between leadership and management. For example 'I'd have thought that most leaders } \\
\text { are able to manage but not all managers would be able to lead.' }\end{array}$ \\
\hline & 2.3 Entrepreneurship & $\begin{array}{l}\text { Comments on the tension between entrepreneurship and leadership. For example 'I'm not so good at working as an } \\
\text { entrepreneur, I'm rather poor. I always feel there is a conflict between myself as a dentist and myself as an entrepreneur.' }\end{array}$ \\
\hline \multirow{2}{*}{$\begin{array}{l}\text { 3. Influence of } \\
\text { culture }\end{array}$} & $\begin{array}{l}\text { 3.1 Seniority, respect } \\
\text { and 'Senpai' }\end{array}$ & $\begin{array}{l}\text { Comments on the role of seniority in leadership. For example 'In Japan, the people at the top have serious power, } \\
\text { experienced senior people lead everything.' }\end{array}$ \\
\hline & 3.2 Relationships & $\begin{array}{l}\text { Comments on the role of relationships in leadership. For example 'It is becoming the top of a team, but is more about } \\
\text { working together with individuals.' }\end{array}$ \\
\hline \multirow{3}{*}{$\begin{array}{l}\text { 4. How do you } \\
\text { become a good } \\
\text { leader }\end{array}$} & 4.1 Role model & $\begin{array}{l}\text { Comments on the participants' role models in leadership. For example 'I follow the leader's back and by doing what } \\
\text { I'm expected to do in my role, leadership follows.' }\end{array}$ \\
\hline & 4.2 Training & $\begin{array}{l}\text { Comments on the role of training in leadership. For example 'I've learnt on the job and l've learnt from my mistakes. I } \\
\text { haven't had any formal training.' }\end{array}$ \\
\hline & 4.3 Barriers & $\begin{array}{l}\text { Comments on potential barriers to leadership. For example 'Working in practice, it's obviously a very consuming job, } \\
\text { very stressful, it can be, and it can be quite tiring and draining, not much energy left.' }\end{array}$ \\
\hline \multirow{3}{*}{ 5. Relevance } & 5.1 Relevance & $\begin{array}{l}\text { Comments on the relevance of leadership in dentistry. For example 'I think it is relevant and very important. We need } \\
\text { to think about this kind of training more in the future. Particularly, because clinics are organised on a small scale and } \\
\text { we need to organise cross-clinic activity.' }\end{array}$ \\
\hline & 5.2 Impact on patients & $\begin{array}{l}\text { Comments on the impact on patients of leadership. For example 'If you've got the right leader at the top then he's } \\
\text { going to influence the way the care is delivered.' }\end{array}$ \\
\hline & 5.3 Future & $\begin{array}{l}\text { Comments on the future and the importance of leadership. For example 'I think that we need to develop quickly and } \\
\text { we need a lot of resources put into that to develop the leadership and leaders and take them forward.' }\end{array}$ \\
\hline
\end{tabular}

importance of role models in Japanese culture:

Tk.1.64 'I learnt from role models, good and bad. Particularly in relation to patient care...'

Tk.3.89 'I see good things in many people and I've learnt from them. I am impressed by people who continuously make the effort to achieve some goals...'

However, given the lack of female role models, the Japanese system can create problems:

Tk.6.83 'In dentistry you do not find any female role models, so I had to look around in other areas for a senior lady...'

Among the Greater Manchester GDPs, role models were considered to be less important:

GM.3.413 'I'm not sure if I do particularly. No... I can't think of anyone... I sort of, ploughed my own furrow...'

GM.4.331 'I come from a self-employed background. I was left in charge of a small retail enterprise when I was 15 so maybe that's where some of the leadership skills come from...'

\section{Code 4.2: Training}

Most of the Japanese participants thought that training was important:

Tk.1.75 'I think training is important... I nurture my own students to be the leaders of the future...'

Tk.2.94 'I think you can be trained in leadership, particularly if you are young...'

Tk.4.83 '...you can train leadership, but experience is important in developing leadership...'

However, the opinions of the clinicians from the North-West differed:

GM.1.487 'I've learnt on the job and I've learnt from my mistakes... I haven't had any formal training'

GM.4.289 'You don't learn it by reading the textbooks... I think some people are just leaders and some people aren't...'

GM.5.298 'You can make people aware of what a good leader is... I don't think you can make somebody a leader...'

GM.6.368 'I think you can hone it but I don't necessarily think you can train it...'

\section{Code 4.3: Barriers}

Allied to the issues expressed above regarding economic imperatives to maintain a profit, some participants highlighted a number of associated barriers to leadership:

GM.2.487 '...time and resources obviously we're dentists, we deliver, we look after patients, we manage practices, we manage businesses, as well as families and everything else...'

GM.3.362 '...time with working in practice, it's obviously a very consuming job, very stressful, and it can be quite tiring and draining, not much energy left...'

\section{Theme 5: relevance}

\section{Code 5.1: Relevance}

In terms of the relevance of leadership, all the participants thought that it was important:

Tk.5.8 '...because most dental teams are many but small, we need leadership to develop consensus across the profession...'

Tk.1.87 '...because clinics are organised 
on a small scale and we need to organise cross-clinic activity...'

Tk.6.116 'In dentistry, I work in a small world, but with leadership training I was able to work in a larger relationship...'

GM.3.267 '...you can just actually see the bigger picture rather than just your own little area of your own little practice...'

\section{Code 5.2: Impact on patients}

Both sets of participants also felt that good leadership impacted on patient care.

Tk.1.8 'Dentists work in small teams, so leadership impacts on the quality of care provided...'

Tk.6.120 '...good leadership improves and is vital to patient care... everyone in the team becomes alive and delivers a better performance...'

GM.2.391 'If you've got the right leader at the top then he's going to influence the way the care is delivered...'

GM.5.354 'I think again it trickles down. If you've got good leadership you tend to have a fairly tightly-knit team which, I think you can tell...'

\section{Code 5.3: Future}

In addition, leadership was seen to be important to the future of dentistry.

Tk.5.146 '...in dentistry, the scale of the office is enlarging and so we need more dentists that can lead...'

GM.2.313 'It's something that the general medical practitioners have had training in and they have had that exposure to leadership, whereas ourselves we haven't and I think that we need to develop quickly and we need a lot of resources put into that to develop the leadership and leaders and take them forward...'

\section{DISCUSSION}

The concept of leadership was considered to be important by GDPs from both Greater Manchester and Tokyo; leadership was seen as providing strategy and direction for a clinical team. This concurs with results from earlier cross-cultural studies, where charisma and team-oriented attributes were universally endorsed as important components in leadership in a non-clinical environment. ${ }^{10}$ It also concurs with earlier research examining the perspectives of GDPs in the UK. ${ }^{11}$

In the academic literature, leadership has been described using two broad themes: 'leadership as the individual' and 'leadership as the relationship.'12,13 The differences in the themes suggest that GDPs from Greater Manchester were more likely to conceptualise leadership using the former taxonomy, using terms that have been previously identified: charisma and intelligence, extraversion, integrity, creativity and self-confidence. ${ }^{13-15}$

In contrast, GDPs from Tokyo described leadership in terms of a cultural and structurally embedded phenomenon. These differences map onto the 'individualism versus collectivism' domain in Hofstede's classical taxonomy of cultural differences in leadership; ${ }^{16,17}$ culture being defined as ' $a$ set of cognitive and evaluative beliefs... that are shared by the members of a social system. ${ }^{18}$

The study also showed the importance of the Japanese collective sense of "community'; respect and 'Senpai' being mentioned by all the participants. The latter is a phrase used to describe a mentoring system in Japanese culture that perpetuates a seniority-based relationship. As such, it demonstrates how important 'role-models' are in the Japanese culture and the value they place on formal training. This aligns with the 'leadership as the relationship' model, which emphasises teamwork, collaboration and interdependence. ${ }^{19}$ It also maps onto earlier research undertaken in a clinical setting where respect and team cohesion were considered as important overarching super-ordinates. ${ }^{20,21}$ However, the study also highlighted how the hierarchical structures found in Japan could present a barrier to leadership. As seniority is ascribed on the basis of age, young GDPs can find it difficult to lead a team when they have to subjugate their authority to older but less senior clinicians.

Both groups of GDPs had a clear understanding of the differences between management and leadership, with the former relating to transactional processes in the 'now', while the latter relating to transformational processes in the future. ${ }^{19,22}$ In the UK, a collaborative leadership style that accounts for individual, situational and transformational factors has been advocated as a way forward for the dental profession. ${ }^{23}$

Culture also influenced the GDPs' views on the importance of education. It was clear from the responses to theme four, that the GDPs from Greater Manchester felt that leadership was a phenomenon that was more within an individual as opposed to one that can be learnt per se. This contrasts with Morison and McMullan's qualitative study, where GDPs felt that education was vital to developing leaders. ${ }^{11}$ The General Dental Council's curriculum framework and guidance on foundation and speciality training all place an emphasis on the demonstration of management and leadership skills. ${ }^{24-26}$ Equally, the review of NHS dental services proposed a need for leadership initiatives and in medicine, the Medical Leadership Competency Framework has been developed to promote learning across five domains: demonstrating personal qualities, working with others, managing services, improving services and setting direction..$^{27,28}$ However, numerous theorists argue that the dominant crucible for learning about leadership is through naturalistic processes and accidental events that is, 'on the job', rather than a deliberate and consciously planned approach to development. ${ }^{29}$

Another important theme that emerged from the study for both groups of GDPs was the expressed tensions between maintaining a viable business and demonstrating leadership in clinical care for their patients. Gupta et al. argue that 'entrepreneurial' leadership is distinct from other behavioural forms of leadership in a competitive environment. ${ }^{30}$ In a similar manner to Burgoyne and Hodgson, ${ }^{29}$ Kempster and Cope $^{31}$ and Macpherson and Holt, ${ }^{32}$ all assert that entrepreneurial learning is experienced within an arena of social relationships that either enable or constrain growth. For the entrepreneur, "this social context places restrictions on his or her action possibilities, which are continually constructed, transformed and negotiated through relationships with those around them: ${ }^{33}$ Dharamsi et al. found that views on social responsibility among dentists was dominated by economic imperatives that can have a negative impact on the policies and practices directing access to care. ${ }^{34}$

Therefore there is a need to take a systemic approach and align structural and regulatory changes with population need and access to services. With the advent of a future prospective payment system impacting upon practice size and a change to working practices through direct access, the importance of leadership will 
become increasingly important, if future services are to be responsive to need, equitable, effective, socially acceptable and efficient. ${ }^{35}$ These issues are important in England as the guiding principles in Securing excellence in commissioning primary care are to ensure services are clinically led, patient focused and outcome focused, with an emphasis on quality. ${ }^{3}$ Although both groups of clinicians saw the importance of leadership for the future, if GDPs are going to lead their profession and take a key role in tackling the health inequalities of their local population and drive up quality ${ }^{3,4}$ they will require both financial encouragement and support from their dental public health colleagues to reorientate their 'down-stream' activity to 'up-stream' action.

Since Darzi, leadership in the UK has been explicitly linked to improving quality, but this will still require financial incentives to ensure service provision is aligned directly with population health needs. ${ }^{36,37}$ It could also benefit from a more structurally embedded approach as is typified in the Japanese model of leadership. The future roles of LPNs could be critical here in co-creating the agenda and drive for change, should they receive enough funding to support their role.

The authors would like to acknowledge and thank the Great Britain Sasakawa Foundation for their award of £2,000 to pay for the travel to Japan. The authors would also like to thank the North-Western Deanery in the United Kingdom for their support for this project.

1. The King's Fund (2011). The future of leadership and management in the NHS: no more heroes. London: The King's Fund, 2011.

2. The King's Fund. Leadership and engagement for improvement in the NHS. London: The King's Fund, 2012.

3. NHS Commissioning Board. Securing excellence in commissioning primary care. London: NHS
Commissioning Board, 2012. Online article available at http://www.england.nhs.uk/wp-content/ uploads/2012/06/ex-comm-pc.pdf (accessed September 2013).

4. NHS Commissioning Board. Securing excellence in commissioning NHS dental services. London: NHS Commissioning Board, 2013. Online article available at www.commissioningboard.nhs.uk/ files/2013/02/commissioning-dental.pdf (accessed September 2013).

5. Health and Social Care Act. London, 2012. Online Act available at http://services.parliament.uk/ bills/2010-11/healthandsocialcare.html (accessed September 2013).

6. Ministry of Health, Labour and Welfare. Outline of the revision of reimbursement of medical fees of 2012. In Annual health, labour and welfare report 2011-2012. Online information available at http:// www.mhlw.go.jp/english/wp/wp-hw6/dl/02e.pdf (accessed September 2013).

7. Braun V, Clarke V. Using thematic analysis in psychology. Qual Res in Psych 2006; 3: 77-101.

8. Carter S, Henderson L. Approaches to qualitative data collection in social science. In Bowling A, Ebrahim

$S$ (eds) Handbook of health research methods. Investigation, measurement and analysis. pp 215-229. Maidenhead: Open University Press, 2007.

9. Willig C. Introducing qualitative research in psychology. Adventures in theory and method. Maidenhead: Open University Press, 2001

10. House R, Javidan M, Hanges P, Dorfman P. Understanding cultures and implicit leadership theories across the globe: an introduction to project GLOBE. J World Bus 2002; 37: 3-10.

11. Morison S, McMullan C. Preparing for the future: challenges and opportunities for management and leadership skills. Br Dent J 2013; 214: E2.

12. Day D V Z Zaccaro S J. Leadership: a critical historical analysis of the influence of leader traits. In Koppes $\mathrm{L} L$ (ed) Historical perspectives in industrial and organizational psychology. pp 383-405. Mahwah, NJ: Erlbaum, 2007

13. Judge T A, Piccolo R F. Transformational and transactional leadership: a meta-analytic test of their relative validity. J Appl Psychol 2004; 89: 755-768.

14. Judge T A, Bono J E, Ilies R, Gerhordt M. Personality and leadership: a qualitative and quantitative review. J Appl Psychol 2002; 87: 765-780

15. Hoffman B J, Woehr D J, Maldagen-Young R, Lyons B D. Great man or great myth? A quantitative review of the relationship between individual differences and leader effectiveness. J Occupat Organ Psych 2011; 84: 347-381

16. Hofstede G. Motivation, leadership, and organization: do American theories apply abroad? Organ Dyn 1980; 9: 42-63.

17. Hofstede G. Cultural constraints in management theories. The Executive 1993: 7: 81-94.

18. House J S. Social structure and personality. In Rosenberg M, Turner R (eds) Social psychology: sociological perspectives. New York: Basic Books, 1981.

19. Alimo-Metcalfe B, Alban-Metcalfe J. Leadership: time for a new direction? Leadership 2005; 1: 51-71.

20. Cameron S, Harbison J, Lambert V, Dickson C. Leadership in community nursing teams. J Adv Nurs 2012; 68: 1469-1481.

21. Cook M J, Leathard H L. Learning for clinical leadership. J Nurs Manag 2004; 12: 436-444.

22. Bass B M. From transactional to transformational leadership: learning to share the vision. Organ Dyn 1990; 19-31.

23. Willcocks S. Leadership theory: implications for developing dental surgeons in primary care? $\mathrm{Br}$ Dent J 2011; 210: 105-107.

24. General Dental Council. Preparing for practice. Dental team learning outcomes for registration. London: GDC, 2011

25. Committee of Postgraduate Dental Deans and Directors. A curriculum for UK dental foundation programme training. London: COPDEND, 2006.

26. Committee of Postgraduate Dental Deans and Directors. The dental gold guide. A reference guide for postgraduate dental speciality training in the UK. 2nd ed. London: COPDEND, 2011.

27. Steele J. NHS dental services in England. An independent review led by Professor Jimmy Steele. London: Department of Health, 2009.

28. Academy of Medical Royal Colleges and NHS Institute for Innovation and Improvement Medical leadership competency framework. 3rd ed. Coventry: NHS Institute for Innovation and Improvement, 2010. Online framework available at http://www.leadershipacademy.nhs.uk/ wp-content/uploads/2012/11/NHSLeadershipLeadership-Framework-Medical-LeadershipCompetency-Framework-3rd-ed.pdf (accessed September 2013).

29. Burgoyne J G, Hodgson V E. Natural learning and managerial action: a phenomenological study in the field setting. J Manage Stud 1983; 20: 387-399.

30. Gupta V, Macmillan I C, Surie G. Entrepreneurial leadership: developing and measuring a cross-cultural construct. J Bus Venturing 2004; 19: 241-260.

31. Kempster $S$, Cope J. Learning to lead in the entrepreneurial context. International Journal of Entrepreneurial Behaviour and Research 2010; 16: $5-34$

32. Macpherson A, Holt R. Knowledge, learning and small firm growth: a systematic review of the evidence. Res Policy 2007; 36: 172-192.

33. Clarke J, Thorpe R, Anderson L, Gold J. It's all action, it's all learning: action learning in SMEs. Journal of European Industrial Training 2006: 30: 441-455

34. Dharamsi S, Pratt D D, MacEntee M I. How dentists account for social responsibility: economic imperatives and professional obligations. J Dent Educ 2007; 71: 1583-1590.

35. Maxwell R J. Quality assessment in health. Br Med J (Clin Res Ed) 1984; 288: 1470-1472.

36. Department of Health. High quality care for all: NHS next stage review final report. London: $\mathrm{DH}, 2008$.

37. Mills I, Batchelor P. Quality indicators: the rationale behind their use in NHS dentistry. Br Dent J 2011; 211: 11-15. 